\title{
Perils of Street Cricket: Two Uncommon Cases of an Eye for a Ball
}

\author{
Leena Mariyam Varghese, Sheetal Savur, Uma Kulkarni \\ (Department of Ophthalmology, Yenepoya Medical College Hospital, Yenepoya University, India)
}

\begin{abstract}
:
Background: Street or gully cricket, a stripped-down-version of international cricket, is a common recreational sport in India. Ocular injuries sustained while playing street cricket though common in youngsters, is often under-reported. Awareness of such ocular injuries and their prevention is poor. Subtle initial injuries can have serious consequences affecting one's vocational and economic status.

Objectives: To highlight two cases of serious ocular injury sustained while playing street cricket, the mechanism of injury and safety measures to prevent them.

Methods: Two youngsters presented with gross diminution of vision following ocular trauma with a cricket ball while fielding without protective eyewear.

Case1: A 16 year old boy manifested with multiple pupillary sphincter tears, lens subluxation, a massive subretinal haemorrhage involving the fovea and angle recession glaucoma.

Case2: A 20 year old male presented with multiple sphincter tears, uveitis and macular oedema.

Results: Both cases had subtle anterior segment and serious posterior segment injuries, caused by a rising trajectory. Both were treated conservatively, first case improved to 6/36 and second was lost to follow up.

Conclusion: Serious vision threatening ocular injuries are seen in cricketers not using protective eyewear. Majority of cricket-related eye injuries can be prevented with the use of protective eyewear, which should be made mandatory at all levels of play. Awareness of such injuries and preventive measures must be created. Cricket ball related ocular injuries warrant thorough evaluation, prompt management and follow up to limit permanent visual impairment.
\end{abstract}

Keywords: Angle recession glaucoma, Berlins edema, Protective wears, Street cricket, Subretinal haemorrhage.

\section{Introduction}

Cricket was first played in $16^{\text {th }}$ century in southern England. By the end of 18th century, it became the national sport of England. Expansion of the British Empire led to cricket being played overseas. The game is now most popular in places like India, South Africa, Australia, England and West Indies. In India, the game is gaining popularity among children and youngsters in the form of street cricket. Street or gully cricket, a stripped-down-version of the international sport of cricket is played in apartment corridors, parking lots, parks, streets, narrow by-lanes, etc.

Blunt trauma by cricket ball causes coup-counter coup effect leading to many vision impairing complications in the eye. Protective headgear and eyewear is commonly used in professional cricket. However, in street cricket, the safety aspects are ignored. In India, there are no reports of descriptive studies on ocular injuries occurring in street or professional cricket.

The aim of this article is not only to report two uncommon cases of vision impairing cricket ball injuries, sustained while playing street cricket, but also to highlight the importance of creating awareness and using ocular protection while playing cricket at all levels.

\section{Materials And Methods}

2.1 Case 1: A 16 year old boy presented to the emergency department with sudden diminution of vision of left eye (LE) following trauma with a cricket ball while playing street cricket. He was fielding about 5 feet away from the batsman at the forward short leg position, when the ball from the bat, hit his hand and bounced up to strike his eye.

On examination, the right eye (RE) was normal. The best corrected visual acuity (BCVA) in the LE was $6 / 60$ (logMAR-1.0). The globe was intact with a clear cornea. The anterior chamber was irregular in depth with grade 2 cells and $2+$ flare. Pupil was round, irregular and dilated $(5 \mathrm{~mm})$, with multiple sphincter tears (Fig.1). The lens was subluxated inferotemporally (Fig.2) with no aphakic area in the pupillary zone. Gonioscopy revealed angle recession in more than two quadrants (Fig.3). Ophthalmoscopy revealed a massive subretinal haemorrhage (Fig.4) of 6 x 4 disc diameters involving the fovea. The intraocular pressure (IOP) was $14 \mathrm{mmHg}$ 
in each eye. He was started on topical antibiotic-steroids (Ciprofloxacin-dexamethasone eye drops) and oral steroids ( Prednisolone $1 \mathrm{mg} / \mathrm{kg}$ body wt).

Five days later, patient developed pain in the eye with worsening of vision to perception of light and a high IOP of 46mmHg. The subretinal hemorrhage appeared larger with central clearing. The patient was advised a vitreoretinal referral but he deferred due to financial reasons. He was started on anti-glaucoma medications $(0.5 \%$ timolol $\mathrm{BD}$ and oral acetazolamide $250 \mathrm{mg}$ TID) to reduce the IOP along with the previous medications for five days. Oral steroids were tapered over 2 weeks \& maintained on a low dose of $5 \mathrm{mg} /$ day for 2 months.

Patient was followed up regularly and after 2 months his vision improved to 6/36 (logMAR-0.78), IOP was under control with medication and subretinal haemorrhage had completely resolved leaving a large chorioretinal scar (Fig.5) adjacent to the fovea and a corresponding central scotoma.

2.2 Case 2: A 20 year old male presented with gross diminution of vision in the right eye following trauma with cricket ball while he was fielding at forward short leg position. The ball hit the ground and then bounced up to hit his eye. He had sudden diminution of vision with mild lid oedema. On examination, his BCVA was 3/60 (logMAR 1.3), pupil was mid dilated with multiple sphincter tears (Fig.6) and his fundus showed macular oedema with a cherry red spot (Berlin's oedema) (Fig.7). His IOP and gonioscopy were normal. He was started on topical antibiotic-steroids (Ofloxacin-dexamethasone) and NSAIDs (Nepafenac) but was lost to follow up after the initial presentation.

\section{Results \& Discussion}

Ocular trauma is one of the major causes for visual disability in the young. Outdoor games are responsible for about $10-20 \%$ of all ocular injuries. ${ }^{[1]}$ Sports related ocular injuries are more common in children probably because of their athletic immaturity and poor supervision while playing outdoor games..$^{[2-4]}$ Such injuries are found more in males of the age group 5-15yrs as they are more adventurous, aggressive and involved more in outdoor activities. ${ }^{[5-8]}$ In western countries, severe ocular injuries due to cricket ball injury are uncommon. ${ }^{[9]}$ Available literature suggests $47 \%$ (34/72) of ocular injuries in children are due to sports. ${ }^{[7]} \mathrm{A}$ study in India, reported cricket to be a common cause of ocular injury. ${ }^{[10]}$ Another study quoted that $15.2 \%$ (33/217) were due to cricket ball. ${ }^{[11]}$ However, the specific types of ocular injuries in cricket and its mechanisms have not been described in any study in India.

The normal human orbit is $40 \mathrm{~mm}$ in height and $35 \mathrm{~mm}$ in width, while, the cricket ball is approximately $70 \mathrm{~mm}$ in diameter .The brow thus offers protection against an object as large as a cricket ball, when the line of approach is horizontal. This is not so, for a rising trajectory, when the ball approaches obliquely from the side or from below as in close fielders, wicket keepers and especially batsmen playing the hook shot. In a case series on ocular injuries in cricket most of the injuries were caused by a rising ball, three of which were due to the hook shot. ${ }^{[9]}$ The hook is a potentially dangerous shot which is played to a short pitched delivery around the head and chest of the batsman and very difficult to control. Since head injury is common, batsmen may wear protective headgears. Protection of the upper face by a visor or cage may be inadequate and there have been reports of severe ocular injury despite using a standard helmet. If the distance between the peak and grille on player's helmet is more, the ball can clear this distance and reach the eye, especially in a rising trajectory obliquely from the side and cause injury. ${ }^{[12]}$

Extent of ocular damage depends on the size, hardness and velocity of the blunt object and the force imparted directly to the eye. Cricket ball is a hard, solid ball made from a core of cork covered by a leather case in professional cricket. In recreational game, rubber ball or soft tennis ball is often used in which case the injury might not be as severe as with a leather ball.

Sports-related blunt injuries include blow out fracture of orbit, globe rupture, lid contusions, sphincter tears, traumatic iritis, subconjunctival hemorrhage, hyphema, commotio retinae, vitreous \& retinal hemorrhage, choroidal rupture, retinal tears and retinal detachment. Considering the potential for eye injury, sports are categorised as low, high, and very high-risk sports. Cricket comes under the high risk category being a hard projectile along with games like hockey, squash, and racquetball. ${ }^{[13,14]}$

Our patients had subtle anterior segment but severe posterior segment injuries which could adversely affect the visual outcome. The final vision in case 1 was $6 / 36$ in the affected eye. Case 2 was lost to follow up with poor visual potential due to macular edema. Such injuries can lead to permanent visual disability in youngsters limiting their employment prospects and increasing their financial liability. Although ocular injuries in cricket have been documented earlier, injury surveillance and documentation of injuries specific to each player (batsmen, fielder, bowler \& wicket keeper) are under-reported.

Most of the cricket-related ocular injuries can be prevented with the proper use of protective eyewear, a concept which is remotely practiced in street cricket. Widespread use of protective eyewear in hockey has shown a significant reduction in ocular injuries. ${ }^{9}$ Contact lens and spectacles do not provide adequate protection. ${ }^{[2]}$ Regular eye glasses have very less impact resistance and glass lenses can increase the seriousness of injuries. ${ }^{[15]}$ An ideal protective eyewear should be made of strong, highly impact-resistant plastic such as polycarbonate, which is eight times stronger than other materials. ${ }^{[2]}$ 
A study found that several misconceptions like experience protects one, prescription lenses are protective, eye guards distort vision and hamper play may be barriers to the use of protective eyewear in sports. ${ }^{[1]}$ Creating awareness about the potential injuries and the importance of the use of safety measures will help in dispelling these myths.

\section{Figures}

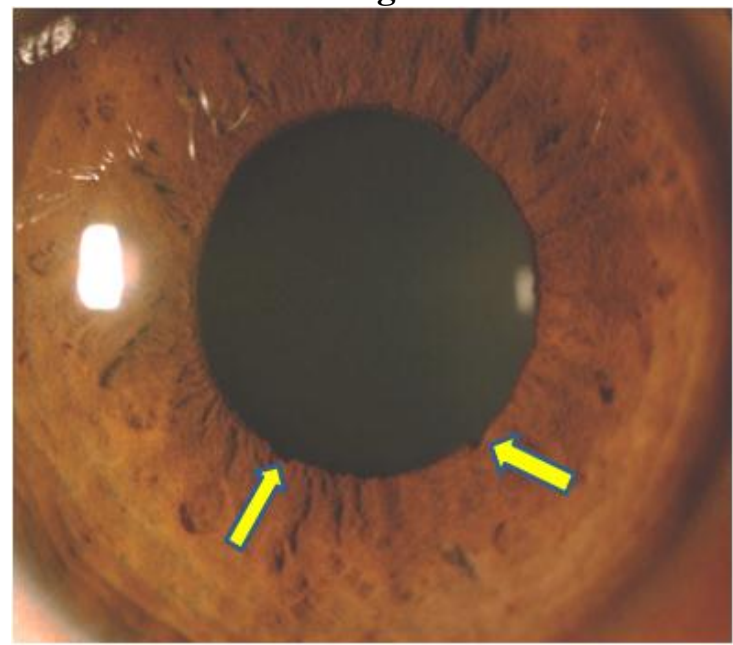

Fig.1. Pupillary sphincter tears seen in case1

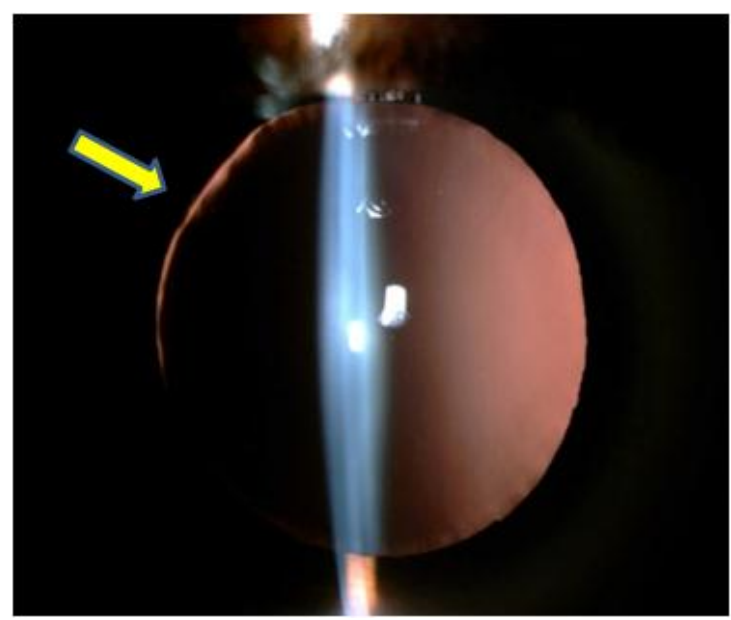

Fig.2. Inferotemporal subluxation of lens with superonasal aphakic area seen on pharmacological pupillary dilation.

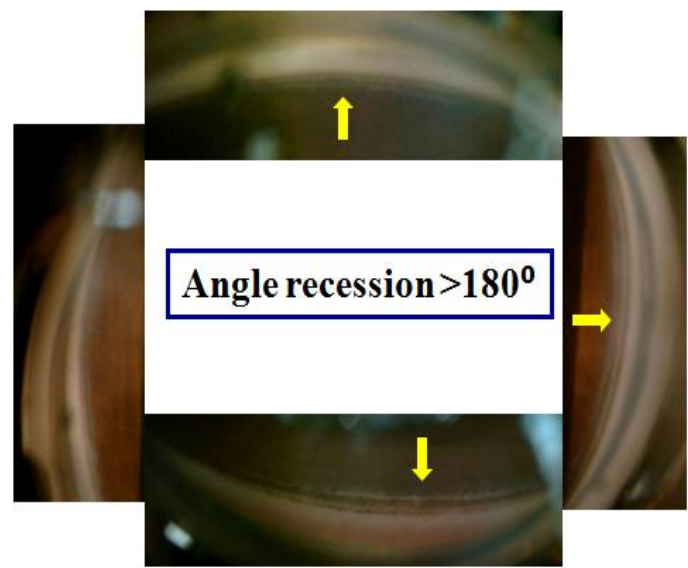

Fig. 3. Gonioscopy showing angle recession $>180^{\circ}$ 


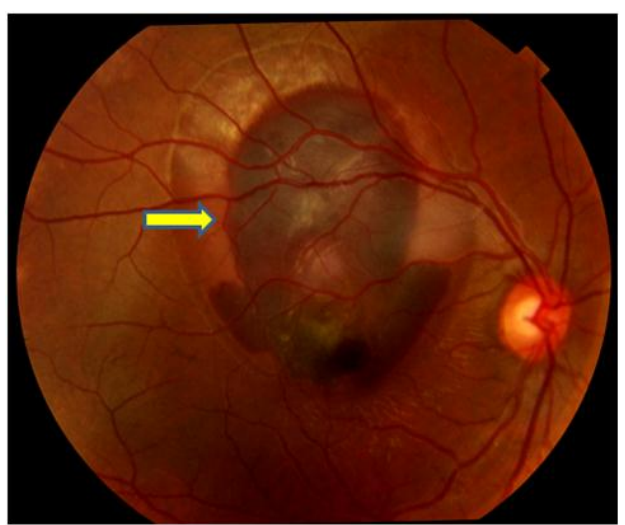

Fig.4. Ophthalmoscopy showing a massive subretinal haemorrhage with surrounding retinal oedema.

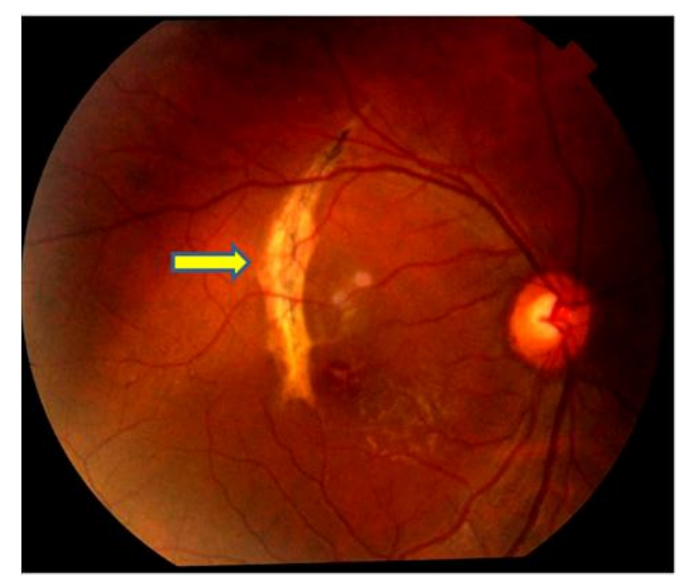

Fig.5. Ophthalmoscopy showing a large chorioretinal scar adjacent to fovea

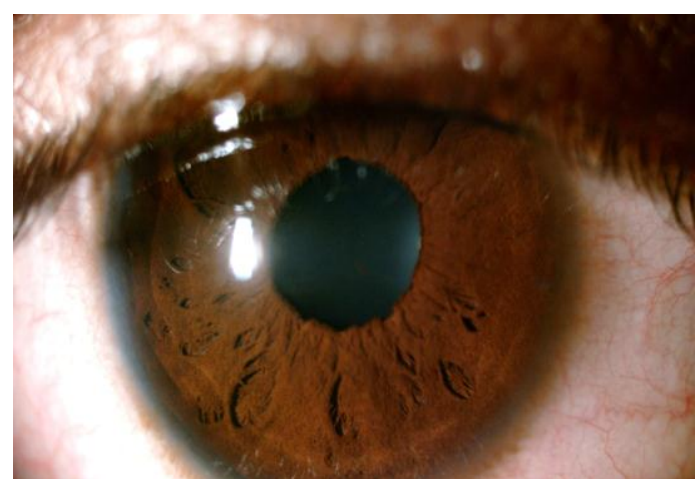

Fig.6. Multiple pupillary sphincter tears seen in case2

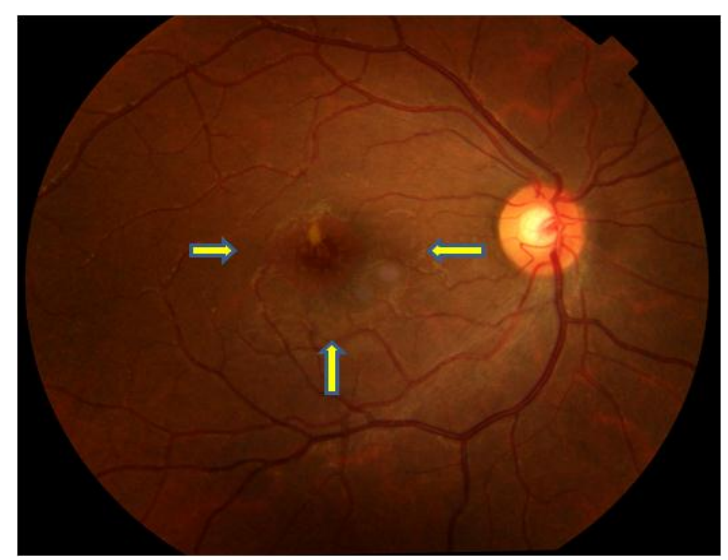

Fig.7. Ophthalmoscopy showing Berlins oedema with cherry red spot. 


\section{Conclusion}

Playing cricket without the use of protective eye wear and headgear can result in serious ocular injuries with permanent visual impairment.

Creating awareness through education of children, parents and teachers regarding the possible sports related eye injuries, its prevention and its prompt management can lead to better visual outcome. Supervision of play, enforcement of game rules and mandatory use of protective eyewear at all levels of play will go a long way in preventing these injuries. Any ocular injury warrants a thorough evaluation and regular follow-up to minimize/limit ocular damage. We suggest that school screening camps be conducted to identify those susceptible to ocular trauma with minor injuries so that they can be advised to avoid high risk sports.

'A cricket ball can make your career if it is hit the right way, but ruin it if one gets hit by the ball the wrong way!'

\section{References}

[1]. Mishra A, Verma A. Sports related ocular injuries. Med J Armed Forces India. 2012 July; 68(3): 260-266. (PMCID: PMC3862938)

[2]. Rodriguez JO, Lavina AM, Agarwal A. Prevention and treatment of common eye injuries in sports. Am Fam Physician.2003;67:1481-1488 (PMID : 12722848)

[3]. Shoja MR, Miratashi AM. Kaur A, Agrawal A. Paediatric ocular trauma. 2006;44:125-130.

[4]. Jaison SG, Silas SE, Daniel R, Chopra SK. A review of childhood admission with perforating ocular injuries in a hospital in northwest India. Indian J Ophthalmol. 1994;42(4):199-201 (PMID:10576997)

[5]. Danadona L, Danadona R, Srinivas M, John RK, McCarty CA, Rao GN. Ocular trauma in an urban population in southern India: the Andhra Pradesh Eye Disease Study. Clin Experiment Ophthalmol.2000;28(5):350-356.(PMID: 11097281)

[6]. Abraham DI, Vitale SI, West SI, Issemel. Epidemiology of eye injuries in rural Tanzania. Ophthalmic Epidemiol.1999;6(2):85-94. (PMID: 10420208)

[7]. Narang S, Gupta V, Simalandhi P, Gupta A, Raj S, Dogra MR. Paediatric open globe injuries. Visual outcome and risk factors for endophthalmitis. Indian J Ophthalmol. 2004;52:29-34. (PMID: 15132376)

[8]. Mac Ewen CJ, Baines PS, Desai T. Eye injuries in children: The current picture. Br J Ophthalmol. 1999; 83:933-36. (PMID10413696)

[9]. Jones NP, Tullo AB. Severe eye injuries in cricket. BritJ.Sports Med. 1986;20(4):178 (PMID:3814991)

[10]. Desai T, Vyas T, Desai S, Malli S. Pattern of ocular injury in paediatric population in western india. Journal of medical sciences 2013;2(2)37-40.

[11]. Desai T, Vyas c, Desai S, Malli S. Pattern of ocular injury in Pediatric Population in western India.NHL Journal of Medical Sciences. 2013;2( 2):37-40.

[12]. Chen H-C, Abedin A. An uncommonly serious case of an uncommon sport injury. Br J Sports Med. 2005;39(8).(PMID: 16046321)

[13]. Washington RL, Bernhardt DT, Brenner JS, Gomez J, Martin JT, et al. Protective eyewear for young athletes. Ophthalmology. 2004;111:600-603.( PMID:14993558)

[14]. Vinger PF, Duma SM, Crandall J. Baseball hardness as a risk factor for eye injuries. Arch Ophthalmol. 1999; 117(3):354-8.(PMID: 10088813)

[15]. Napier SM, Baker RS, Sanford DG, Easterbrook M. Eye injuries in athletics and recreation. Surv Ophthalmol. 1996; 41(3):229-44. (PMID:8970237) 